\title{
DURUS AL-LUGHAH GONTORY: MEDIA PEMBELAJARAN BAHASA ARAB UNTUK PEMULA MENGGUNAKAN METODE LANGSUNG
}

\author{
Dihin Muriyatmoko1, Faisal Reza Pradhana², Zaenury Adhiim Musyafa' ${ }^{3}$ \\ 1,2,3 Teknik Informatika Universitas Darussalam Gontor Ponorogo \\ Email: ${ }^{1}$ dihin@unida.gontor.ac.id, ${ }^{2}$ faisalrezapradhana@unida.gontor.ac.id, ${ }^{3}$ adhiimzaenury@ gmail.com
}

(Naskah masuk: 16 November 2018, diterima untuk diterbitkan: 18 Desember 2018)

\begin{abstract}
Abstrak
Setiap lembaga pendidikan berbasis pesantren mewajibkan santrinya untuk mempelajari bahasa arab, salah satunya Universitas Darussalam Gontor (UNIDA Gontor) Ponorogo yang kesehariannya menggunakan bahasa arab sebagai sarana komunikasi. Media pembelajaran bahasa arab ini bertujuan untuk membantu calon mahasiswa bukan alumni pesantren yang ingin bergabung menjadi mahasiswa UNIDA Gontor. Konten aplikasi diambil dari buku Durus Al-Lughah karya K.H. Imam Zarkasyi yang merupakan satu dari tiga pendiri Pondok Modern Darussalam Gontor (PMDG) Ponorogo dan salah satu muridnya yaitu K.H. Imam Syubani, buku ini juga dipelajari santri PMDG kelas satu. Media ini berbasis mobile Android yang dibuat menggunakan langkah-langkah model Waterfall dan kontennya menerapkan metode langsung tanpa menggunakan bahasa ibu (Indonesia). Media ini merupakan pengembangan dari sebelumnya yang menggunakan metode terjemah yang memiliki kelemahan penguasaan bahasa menjadi pasif dan pencapaian pengetahuan kata-kata kurang sempurna. Pengujian dilakukan dengan dua cara yaitu kesesuaian pada berbagai perangkat Android menunjukkan kesesuaian untuk perangkat berukuran minimal 4.5 inchi dan penyebaran kuisioner dengan nilai rata-rata dari seorang ahli materi pembelajaran bahasa Arab memberikan nilai 100\%, seorang ahli media pembelajaran 93,34\%, mahasiswa bukan alumni pesantren 90,5\%, hasil penilaian dari mahasiswa Prodi Pendidikan Bahasa Arab (PBA) 92\% dan hasil penilaian dari pengguna umum playstore (bit.ly/durusdm) mulai tanggal 1 sampai 20 Mei 2018 menghasilkan nilai 5 dari 5 (total rating tertinggi) berjumlah 31 orang. Hasil kuisioner oleh responden menunjukkan kesesuaian media dengan pengguna tingkat pemula, akan tetapi aplikasi ini hanya bersifat membantu dan tidak bisa menggantikan peran guru dan interaksi antar guru dengan murid yang sesungguhnya.
\end{abstract}

Kata kunci: durus al-lughah, Gontor, media pembelajaran bahasa arab, metode langsung, pesantren

\section{DURUS AL-LUGHAH GONTORY: ARABIC LEARNING MEDIA FOR BEGINNER USING DIRECT METHOD}

\begin{abstract}
Every educational institution based on Islamic boarding school requires their students to learn Arabic, one of them is UNIDA Ponorogo are in daily use Arabic as a means of communication. This goal of Arabic learning media is to help the candidate of non-alumni Islamic boarding schools who want to join as a student at UNIDA Gontor. This content media taken from Durus Al-Lughah book by Imam Zarkasyi who was one of three founders of PMDG Ponorogo and his student Imam Syubani, it's also studied by the student of PMDG at beginner class. Android mobile-based application created using the waterfall model and the content is applied the direct method without using mother tongue (Indonesian). This media is the development of previous applications that use the method of translation that have the weakness of mastery of the language to be passive and the achievement of knowledge words less than perfect. Testing is done in two ways that the suitability of various Android devices indicate the suitability for the device size of at least 4.5 inches and distribution of questionnaires average value of an expert in Arab language learning material gives 100\%, an expert in media learning 93.34\%, the student is nonalumni Islamic boarding schools 90.5\%, the results of the assessment of Arabic Language Teaching program 92\% and results in assessment of general users play store (bit.ly/durusdm) starting on May 1 to 20, 2018, produces the highest value amounted to 31 . The results of questionnaires by respondents indicate that media is suitability for beginner level users, but this media is only helpful and cannot replace the role of teachers and the real interaction between teachers and students.
\end{abstract}

Keywords: durus al-lughah, Gontor, arabic mobile learning, direct method, Islamic boarding school 


\section{PENDAHULUAN}

Al-Qur'an merupakan kitab pedoman umat muslim yang menunjukkan tanda atau isyarat tentang ilmu pengetahuan yang ditulis menggunakan bahasa Arab (Naik, 1997). Tidak bisa pungkiri, pendalaman bahasa Arab sangat diperlukan untuk menambah pengetahuan dan pemahaman wajib bagi seorang muslim (Andriani, 2015). Sebagaimana dalam AlQur'an Surat Yusuf ayat 12 berikut ini:

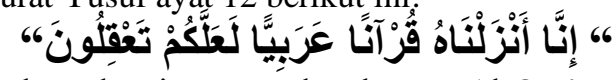

“Sesungguhnya kami menurunkan berupa Al-Qur'an dengan bahasa Arab, agar kamu memahaminya" (QS Yusuf:12) (Ali, 2011).

Negara Indonesia memiliki keunikan dan kekayaan tersendiri yang tidak ada pada negara lain yaitu sistem pendidikan berbasis pondok pesantren (Nurochim, 2016), yang mempelajari Bahasa Arab dan agama Islam sebagai pendidikan karakter (Syafe'i, 2017). Salah satu institusi pendidikan yang berbasis pesantren yaitu PMDG Ponorogo, Jawa Timur Indonesia, yang setara dengan SMP-SMA (Syarifah, 2016) dan Pendidikan Tinggi UNIDA Gontor yang menyelenggarakan program sarjana dan pascasarjana dengan berbagai Program Studi (Prodi).

Penelitian ini merupakan pengembangan dari sebelumnya yaitu Durus Al-Lughah jilid 1 yang pada bagian kontennya menerapkan metode terjemah, metode tersebut menggunakan bahasa ibu (Bahasa Indonesia) pada inti pembelajaran di setiap babnya (Muriyatmoko\&Abdullah, 2017), (Abdullah\& Musyafa', 2018) yang dikhususkan bagi pengguna dari negara Indonesia. Konten diambil berasal dari buku Durus Al-Lughah Al-Arabiyah yang merupakan buku pembelajaran bahasa Arab karya KH. Imam Zarkasyi dan KH. Imam Syubani yang saat ini digunakan salah satu media ajar untuk pendidikan pondok pesantren yakni di 20 cabang PMDG dan lebih dari 380 pondok alumni yang tersebar diseluruh pelosok Indonesia (Indonesia, 2016). Buku tersebut merupakan media belajar bahasa Arab yang mengutamakan metode langsung (direct method) pada tahap awal pembelajaran dan menggunakan metode lain pada tahap lanjutannya (Zarkasyi\&Syubani, n.d.).

Target media ini lebih dikhususkan untuk calon mahasiswa UNIDA Gontor yang bukan alumni pondok (SMA/SMK/MA) karena mereka kurang memiliki dasar kemampuan berbahasa Arab sesuai standar, yang mana saat ini sedang mengikuti matrikulasi Bahasa selama satu tahun.

Media ini dibuat menggunakan ponsel pintar yang berbasis Android, dikarenakan paling populer di dunia yang memberdayakan ratusan juta perangkat seluler lebih dari 190 negara di seluruh dunia dan sifat dari kode program dikeluarkan oleh perusahaan Google dengan memiliki lisensi open source atau semua pihak memiliki kebebasan penuh, sehingga menarik bagi para pengembang dan perusahaan (Developer, 2018).
Tabel 1. Rencana integrasi buku Durus Al-Lughah menuju Android mobile apps

\begin{tabular}{cccc}
\hline Buku & Metode & Kategori & Status \\
\hline Jilid 1 Bab 1 - 12 & Terjemah & Dasar & Selesai \\
\hline Jilid 1 Bab 1 - 12 & Langsung & Dasar & Selesai \\
\hline Jilid 1 Bab 2 - 24 & Terjemah & Medium & Proses \\
\hline Jilid 1 Bab 2 - 24 & Langsung & Medium & Proses \\
\hline Jilid 2 Bab 1 - 12 & Terjemah & Medium & Proses \\
\hline Jilid 2 Bab 1 - 12 & Langsung & Medium & Proses \\
\hline Jilid 2 Bab 2 - 24 & Terjemah & Tinggi & Proses \\
\hline Jilid 2 Bab 2 - 24 & Langsung & Tinggi & Proses \\
\hline
\end{tabular}

Tabel 1 adalah rencana pengembangan aplikasi yang dibagi menjadi tiga kategori yaitu dasar, medium dan tinggi sesuai level penggunanya. Dengan adanya aplikasi Durus Al-lughah jilid 1 sebelumnya dapat mempermudah mahasiswa yang baru belajar Bahasa Arab, namun disisi lain dalam proses pembelajaran yang menggunakan bahasa Indonesia sebagai pengantarnya, menjadikan penguasaan bahasa pasif dan pencapaian pengetahuan kata-kata kurang sempurna. Menurut penelitian dari penerapan metode terjemah, proses pencapaian bahasa target oleh siswa akan terhambat, maka dari itu metode ini tidak direkomendasikan (Zaid, 2012). Oleh karena itu media ini dikembangkan dengan menerapkan metode langsung pada kontennya dan menggunakan pendekatan waterfall untuk proses pembuatannya karena metode tersebut sesuai digunakan pada saat spesifikasi kebutuhan sudah lengkap dan jelas (Dima \& Maassen, 2018), serta memang sudah ada aplikasi sebelumnya yang diverifikasi kelemahan metodenya.

Penelitian lain yang menggunakan media ponsel pintar, pertama, tentang evaluasi advanced media arabic memberikan hasil sangat baik $(83,6 \%)$ berdasarkan evaluasi, media sesuai dan dapat dipakai untuk siapa saja yang tertarik dibidang bahasa arab dikarenakan isi bahasa didasarkan pada materi otentik yang diambil dari bahasa arab yang sangat berkualitas (Rahman, 2012), kedua, riset yang menganalisis studi empiris terhadap 36 artikel tentang penggunaan ponsel pintar pada perguruan tinggi menunjukkan hasil yang masih terbatas dan ekspektasi bahwa ponsel pintar dapat ditransformasikan ke pembelajaran tidak dapat ditetapkan dikarenakan sebagian besar proses pembelajaran masih menggunakan paradigma dari buku petunjuk (Pimmer,dkk., 2016).

Keterbaruan dari riset ini ada pada kontennya, yang sudah terbukti menghasilkan lulusan PMDG yang tersebar menjadi tokoh umat di Indonesia yang mahir berbahasa arab, diantaranya Ahmad Fuad Effendi, Emha Ainun Nadjib, Hidayat Nur Wahid, Idham Chalid, Lukman Hakim Saifudin, Bachtiar Nasir, Din Syamsuddin, Hazim Muzadi dan lain -lain. Keterbaruan yang lain terdapat pada metodenya yang menggunakan metode langsung tanpa penggunaan terjemahan dalam Bahasa Indonesia yang terdapat pada bagian kosa kata, contoh kalimat, dan percakapannya. 


\section{BAHAN DAN METODE}

\section{A. Bahan}

Bahasa pemrograman java sebagai back-end dan xml untuk desain front-end digunakan untuk mengembangkan media ini. Perangkat lunak open source buatan Google yaitu Android Studio serta SQlite sebagai basis data yang untuk menyimpan soal ujian dibagian akhir konten.

\section{B. Metode}

Metode penelitian menggunakan waterfall atau sering disebut pendekatan air terjun pada gambar 1 dan hasil dari semua tahapnya diperinci pada bab 3 .

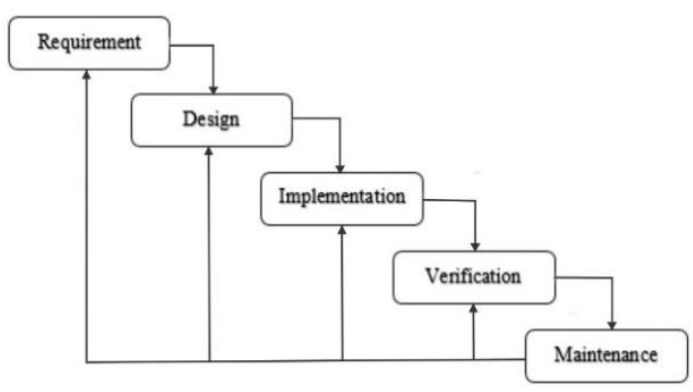

Gambar 1. Metode Waterfall (Bassil, 2012)

Metode langsung atau dalam istilah bahasa Arab disebut Thoriiqoh mubaasyiroh ( طريقة مباشرة ) muncul karena penolakan terhadap metode qowaid atau terjemah yang mana bahasa dalam metode ini tidak digunakan secara langsung (Bakri, 2017). Metode ini muncul sejak tahun 1850 dan menjadikan pembelajaran bahasa asing menjadi efektif, hidup dan menyenangkan. Metode langsung menjadi perkembangan dan perubahan dalam pembelajaran bahasa asing (Marlina, 2016). Metode langsung pada riset ini diterapkan pada bagian kosa kata, contoh kalimat, dan percakapan tanpa bantuan bahasa Indonesia tetapi menggunakan bantuan gambar dan suara. Beberapa penjelasan yang digunakan dalam metode langsung ini diantaranya:

- Tujuan dasar untuk mengembangkan kemampuan dalam berfikir dengan bahasa Arab dan bukan dengan bahasa ibu (bahasa Indonesia)

- Sepantasnya pembelajaran bahasa Arab menggunakan bahasa asli (bahasa Arab) tanpa diterjemahkan kedalam bahasa Indonesia

- Pelajar tingkat pemula mempelajari bahasa Arab sebagai bahasa kedua dan mendengarkan ke dalam kalimat yang sempurna yang mempunyai arti yang jelas

- Mengembangkan kemampuan dalam berfikir dan mengambil kesimpulan serta menyerap kata-kata bahasa Arab secara langsung (Thu'aimah, 2001)

\section{HASIL DAN PEMBAHASAN}

\section{A. Requirement}

Tabel 2 merupakan tahap penjajakan, mulai penggalian dan perumusan masalah hingga solusi teknologi yang digunakan dalam pengembangan media pembelajaran Bahasa arab ini. Penggalian kebutuhan berawal dari Lembaga Bahasa UNIDA
Gontor yang memandang perlunya pengembangan metode pembelajaran Bahasa arab berbasis online dan Android karena tuntutan zaman (Web Journalist, 2015).

\begin{tabular}{|c|c|c|}
\hline No & Kegiatan & Hasil \\
\hline 1 & $\begin{array}{l}\text { Identifikasi } \\
\text { masalah }\end{array}$ & $\begin{array}{l}\text { Banyak calon mahasiswa bukan } \\
\text { alumni pesantren (SMK/SMA) tidak } \\
\text { lulus saat ujian mahasiswa baru } \\
\text { sehingga mengikuti program } \\
\text { matrikulasi bahasa selama satu tahun }\end{array}$ \\
\hline 2 & $\begin{array}{l}\text { Konten/Isi dari } \\
\text { aplikasi }\end{array}$ & $\begin{array}{l}\text { Referensi buku bahasa Arab Durus } \\
\text { Al-Lughah jilid } 1 \text { bab } 1-12\end{array}$ \\
\hline 3 & $\begin{array}{l}\text { Metode } \\
\text { pengajaran }\end{array}$ & Menggunakan metode langsung \\
\hline 4 & $\begin{array}{l}\text { Solusi yang } \\
\text { ditawarkan }\end{array}$ & $\begin{array}{l}\text { Konten media berbasis Android } \\
\text { menggunakan metode langsung }\end{array}$ \\
\hline 5 & $\begin{array}{l}\text { Teknologi yang } \\
\text { digunakan }\end{array}$ & $\begin{array}{l}\text { Media pembelajaran bahasa Arab } \\
\text { berbasis mobile }\end{array}$ \\
\hline
\end{tabular}

Setelah tahap awal, dilanjutkan tahap perumusan konten dan desain kasar user interface dan user experience, dengan bantuan ahli materi dan ahli media pembelajaran Bahasa Arab yang ada di Lembaga Bahasa UNIDA Gontor untuk memastikan bahwa media dan konten sesuai untuk pemula, sesuai tabel 3.

Tabel 3. Konten media pembelajaran Bahasa arab

\begin{tabular}{|c|c|}
\hline Bab & Materi \\
\hline 1 & Penggunaan kata benda dan kata tunjuk mudzakkar (laki-laki) \\
\hline 2 & $\begin{array}{l}\text { Penggunaan kata benda dan kata tunjuk mudzakkar (laki-laki) } \\
\text { dan mu'annas (perempuan) }\end{array}$ \\
\hline 3 & $\begin{array}{l}\text { Perbedaan penggunaan kata benda dan kata tunjuk } \\
\text { mudzakkar (laki-laki) dan mu'annas (perempuan) }\end{array}$ \\
\hline 4 & $\begin{array}{l}\text { Penggunaan dan penyebutan penunjukan kata benda dengan } \\
\text { "di sini" dan "di sana" }\end{array}$ \\
\hline 5 & $\begin{array}{l}\text { Penggunaan dan pernyataan posisi benda dengan huruf jar } \\
\text { dan zharf (diatas, di dalam, di bawah, di antara, di belakang, } \\
\text { di depan, di atas (tidak menempel) }\end{array}$ \\
\hline 6 & $\begin{array}{l}\text { Penggunaan yang menyatakan kata benda } \\
\text { dhamir/kepemilikan (kepunyaan kamu laki-laki, kamu } \\
\text { perempuan, saya, dia laki-laki dan dia perempuan) beberapa } \\
\text { kata benda dasar }\end{array}$ \\
\hline 7 & $\begin{array}{l}\text { Penggunaan yang menyatakan kata } r \text { benda } \\
\text { dhamir/kepemilikan (kepunyaan kamu laki-laki, kamu } \\
\text { perempuan, saya, dia laki-laki dan dia perempuan) beberapa } \\
\text { kata benda lanjutan }\end{array}$ \\
\hline 8 & $\begin{array}{l}\text { Penggunaan angka (mufrad dan jama') untuk mudzakkar } \\
\text { (laki-laki) pada sebuah kalimat }\end{array}$ \\
\hline 9 & $\begin{array}{l}\text { Perbedaan penggunaan angka (mufrad dan jama') untuk } \\
\text { mudzakkar (laki-laki) dan mu'annas (perempuan) pada } \\
\text { sebuah kalimat (kata benda dasar) }\end{array}$ \\
\hline 10 & $\begin{array}{l}\text { Perbedaan penggunaan angka (mufrad dan jama') untuk } \\
\text { mudzakkar (laki-laki) dan mu'annas (perempuan) pada } \\
\text { kalimat (kata benda lanjutan) }\end{array}$ \\
\hline 11 & $\begin{array}{l}\text { Penggunaan kata laisa / bukannya (saya, kita, kamu } \\
\text { perempuan, kamu laki-laki, dia perempuan dan dia laki-laki) }\end{array}$ \\
\hline 12 & Penggunaan perhitungan laki-laki (11-20) di dalam kalimat \\
\hline
\end{tabular}

\section{B. Design}

Setelah mengetahui konten yang telah dirancang, selanjutnya pembuatan alur langkah-langkah penggunaan media pembelajaran, sesuai gambar 2, dimulai dari splash screen, menu utama, menu opsi dan latihan soal. 
80 Jurnal Teknologi Informasi dan Ilmu Komputer (JTIIK), Vol. 6 No. 1, Februari 2019, hlm. 77-84

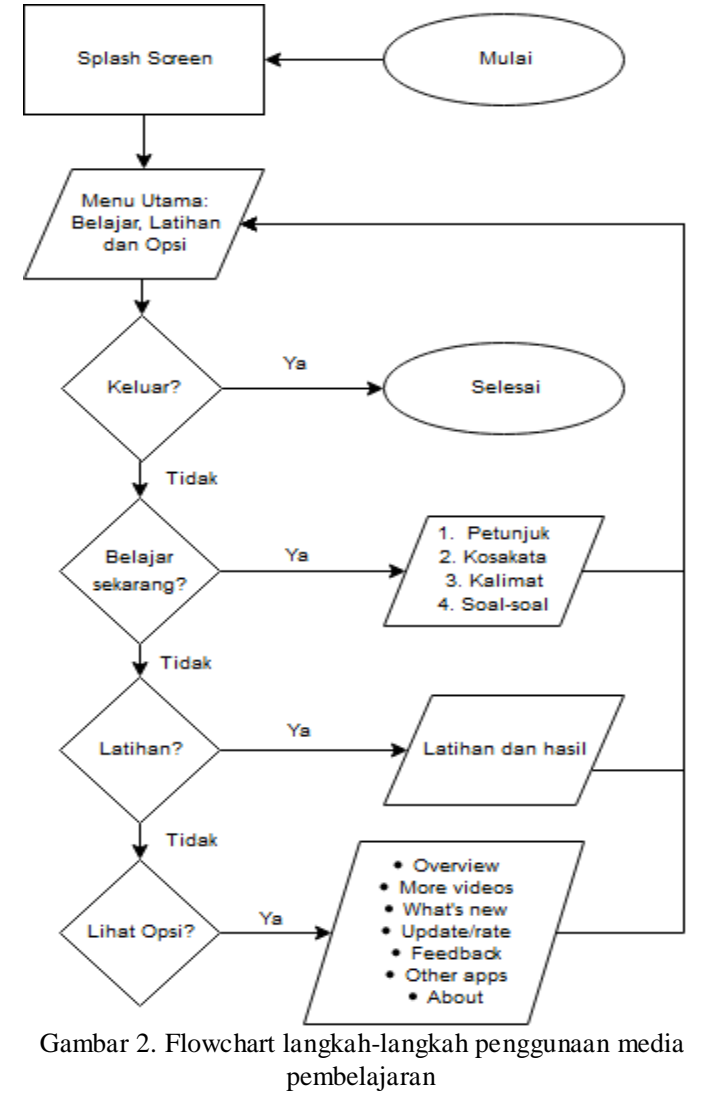

\section{Implementation}
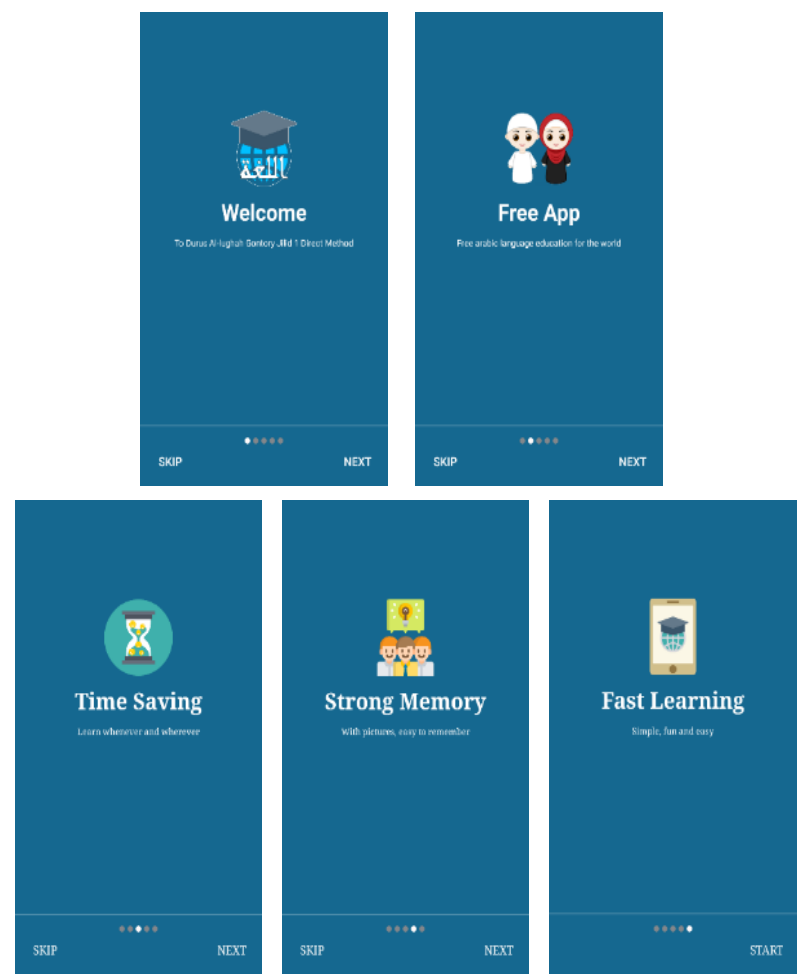

Gambar 3. Welcome screen

Gambar 3, menunjukkan tampilan ketika pengguna membuka pertama kali media ini, berisi keterangan ucapan selamat datang, kesesuaian pengguna, penghematan waktu dan belajar cepat.

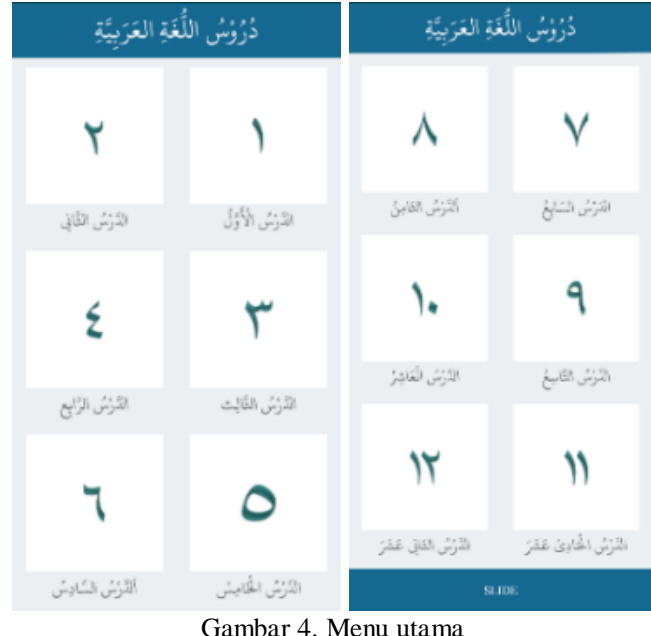

Gambar 4, halaman yang menunjukkan tiap bab pembelajaran bahasa Arab dari bab 1 -12.
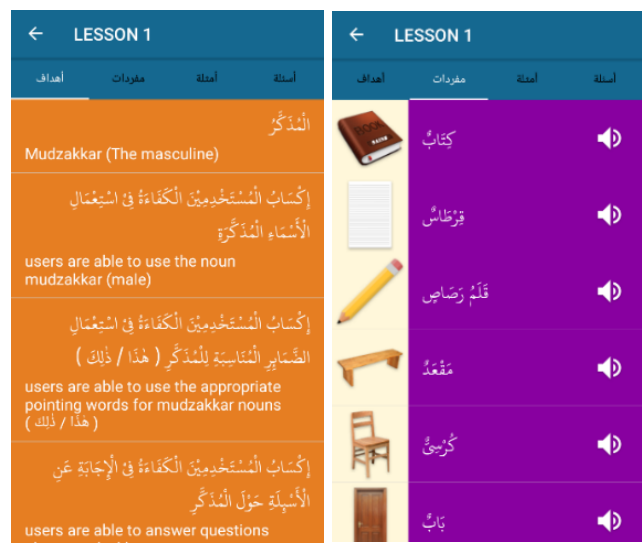

Gambar 5. Halaman petunjuk

Gambar 5, tampilan halaman utama aplikasi setelah pengguna masuk ke dalam salah satu bab. Menerangkan tujuan belajar yang ingin dicapai dan menyediakan media gambar dan arti menggunakan bahasa Inggris tidak menggunakan bahasa Indonesia. Gambar 5 sebelah kanan merupakan penerapan metode langsung dengan menggunakan kata dalam huruf arab sehingga mudah diingat dikemudian hari.

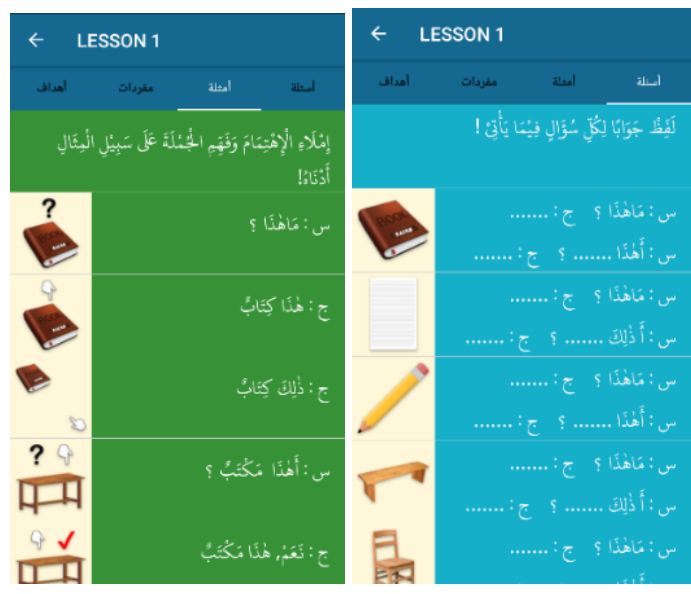

Gambar 6. Halaman contoh kalimat 
Gambar 6 menyajikan gambar dan contoh kalimat tiap bab, menggunakan kalimat bahasa Arab yang berisi inti pembelajaran yang ingin dicapai dan sebelah kanan berisi contoh soal. Pengguna dapat menjawab dengan menggunakan angan-angan secara langsung untuk menguji pemahaman.

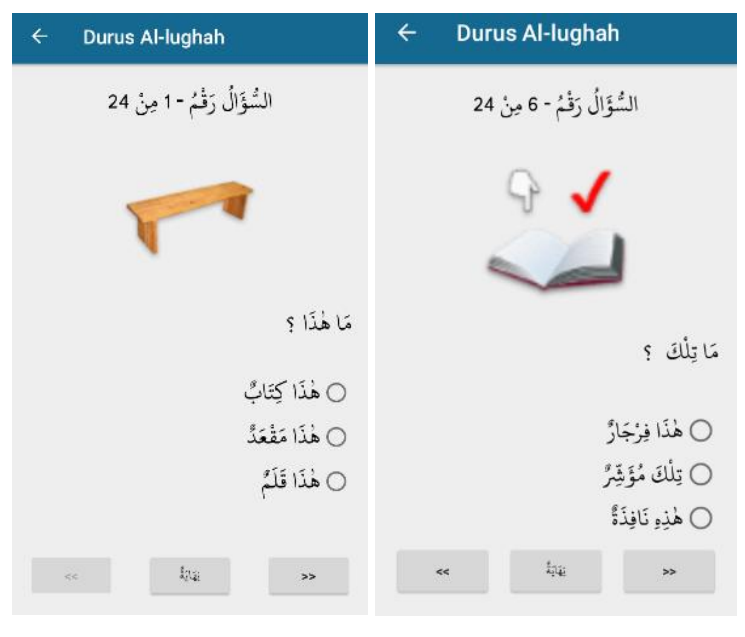

Gambar 7. Halaman latihan

Gambar 7, merupakan kumpulan dari soal-soal pilihan ganda untuk pengujian hasil pembelajaran materi untuk mengetahui sejauh mana pengguna menguasai materi tiap bab. Terdapat menu sebelum dan sesudah untuk kembali atau meneruskan soal ke halaman yang diinginkan. Hasil akan muncul ketika pengguna menekan tombol selesai.

\section{Verification}

\section{- Uji Fungsionalitas Software}

\begin{tabular}{clcc}
\multicolumn{3}{c}{ Tabel 4. Kesesuaian tipe perangkat dan ukuran layar } \\
\hline No & Merek dan tipe perangkat & $\begin{array}{c}\text { Layar } \\
\text { (Inchi) }\end{array}$ & $\begin{array}{c}\text { Hasil } \\
\text { sesuai }\end{array}$ \\
\hline 1 & Smartfren A16C3H (A16C3H) & 4.5 & Ya \\
\hline 2 & Lenovo TAB 2 A7-30HC & 7 & Ya \\
\hline 3 & Asus ZenFone Go & 4.5 & Ya \\
\hline 4 & Oppo CPH1701 (CPH1701) & 5.2 & Ya \\
\hline 5 & Lenovo P1 (P1a42) & 5.5 & Ya \\
\hline 6 & Vivo Y31L (Y31L) & 4.7 & Ya \\
\hline 7 & Vivo Y35 & 5 & Ya \\
\hline 8 & Samsung Galaxy A5(2017) & 5.2 & Ya \\
\hline 9 & Xiaomi Redmi 3 (ido) & 5 & Ya \\
\hline 10 & Samsung Galaxy J3(2017) & 5.5 & Ya \\
\hline 11 & Samsung Galaxy J5 Pro & 5.2 & Ya \\
\hline 12 & Xiaomi MI 5C (meri) & 5.5 & Ya \\
\hline 13 & Xiaomi Redmi Note 4 (mido) & 5.5 & Ya \\
\hline 14 & Xiaomi Redmi 5A (riva) & 5 & Ya \\
\hline 15 & Xiaomi Redmi 4X (santoni) & 5 & Ya \\
\hline 16 & Samsung Galaxy S Duos3 & 4 & Tidak \\
\hline 17 & Samsung Galaxy J1 & 4.3 & Tidak \\
\hline 18 & Samsung Galaxy J1 Ace & 4.3 & Tidak \\
\hline 19 & Andromax i & 4 & Tidak \\
\hline 20 & Advan digital S4Z & 4 & Tidak \\
\hline & & &
\end{tabular}

Kesesuaian tipe perangkat dan ukuran layar yang telah diinstal di beberapa perangkat Android pada table 4, menunjukkan bahwa media ini sesuai untuk perangkat berukuran minimal 4,5 inchi.

\section{- Uji Materi Pembelajaran}

Pengujian ini bertujuan untuk mengecek hasil materi/konten yang ada didalam aplikasi sebagai bahan pembelajaran untuk para pengguna. Pengujian ini diberikan kepada seorang ahli materi bahasa Arab di UNIDA Gontor (Al-Ustadz Dr. Abdul Hafidz Zaid, Lc, M.A.) beliau merupakan Ketua Prodi Magister PBA, Wakil Rektor 3 dan Guru Senior sekaligus ahli Bahasa arab di PMDG. Hasil kuisioner ditunjukkan pada table 5 berikut ini

\begin{tabular}{clc}
\multicolumn{3}{l}{ Tabel 5. Hasil Kuisioner ahli materi pembelajaran } \\
\hline No & \multicolumn{1}{c}{ Unsur } & Nilai \\
\hline 1 & Kejelasan penyajian materi & 5 \\
\hline 2 & $\begin{array}{l}\text { Materi dalam media relevan dengan } \\
\text { materi yang harus dipelajari murid }\end{array}$ & 5 \\
\hline 3 & $\begin{array}{l}\text { Konsep media dengan materi benar } \\
\text { dan tepat }\end{array}$ & 5 \\
\hline 4 & Struktur media memudahkan pemakai & 5 \\
\hline 5 & $\begin{array}{l}\text { Tujuan pembelajaran media sesuai } \\
\text { dengan materi }\end{array}$ & 5 \\
\hline 6 & $\begin{array}{l}\text { Media mendorong murid untu } \\
\text { memperdalam isi materi }\end{array}$ & 5 \\
\hline 7 & Penyajian komunikatif dan interaktif & 5 \\
\hline 8 & Sistem / alur / logika jelas & 5 \\
\hline 9 & $\begin{array}{l}\text { Ilustrasi gambar pada soal latihan } \\
\text { relevan dengan materi }\end{array}$ & 5 \\
\hline 10 & Media tidak menimbulkan ambiguitas & 5 \\
\hline 11 & Membantu efektifitas pembelajaran & 5 \\
\hline 12 & Meningkatkan pemahaman murid & 5 \\
\hline \multicolumn{3}{c}{ Rata - rata } \\
\hline
\end{tabular}

Selain itu materi pembelajaran diuji oleh 7 orang Mahasiswa Prodi PBA dari semester 6 dan semester 8 . Hasil penilaian bisa dilihat pada Gambar 8 yang menunjukkan nilai rata-rata $92 \%$.

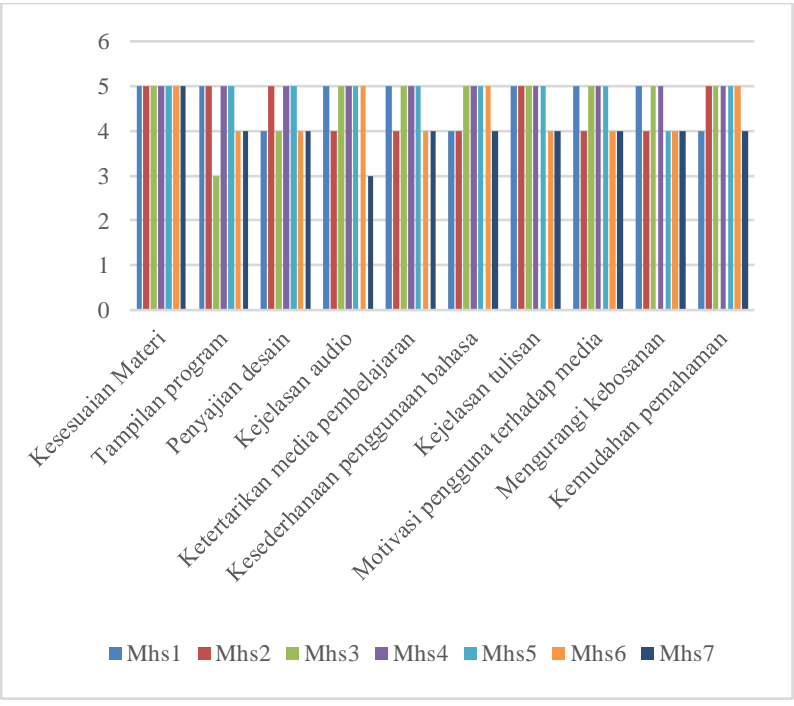

Gambar 8. Penilaian Mahasiswa Prodi PBA 


\section{- Uji Media Pembelajaran}

Pengujian ini bertujuan untuk mengecek dari aspek desain, aspek gambar, aspek suara, aspek tulisan, aspek pemrograman. Pengujian ini diberikan kepada seorang ahli media pembelajaran di PMDG dan kaprodi PBA di UNIDA Gontor (Al-Ustadz KH. Agus Budiman, S.Ag, M.Pd). Hasil kuisoner penilaian beliau memberikan nilai rata-rata $93.34 \%$.

- Uji terhadap mahasiswa non KMI/Martikulasi Hasil kuisioner diperuntukkan bagi mahasiswa non-alumni pesantren atau mahasiswa martikulasi Bahasa ditunjukkan pada gambar 9. Hasil dari kuisioner tersebut adalah sampel 4 dari 30 responden menunjukkan bahwa media ini diminati mereka dengan nilai $90.5 \%$.

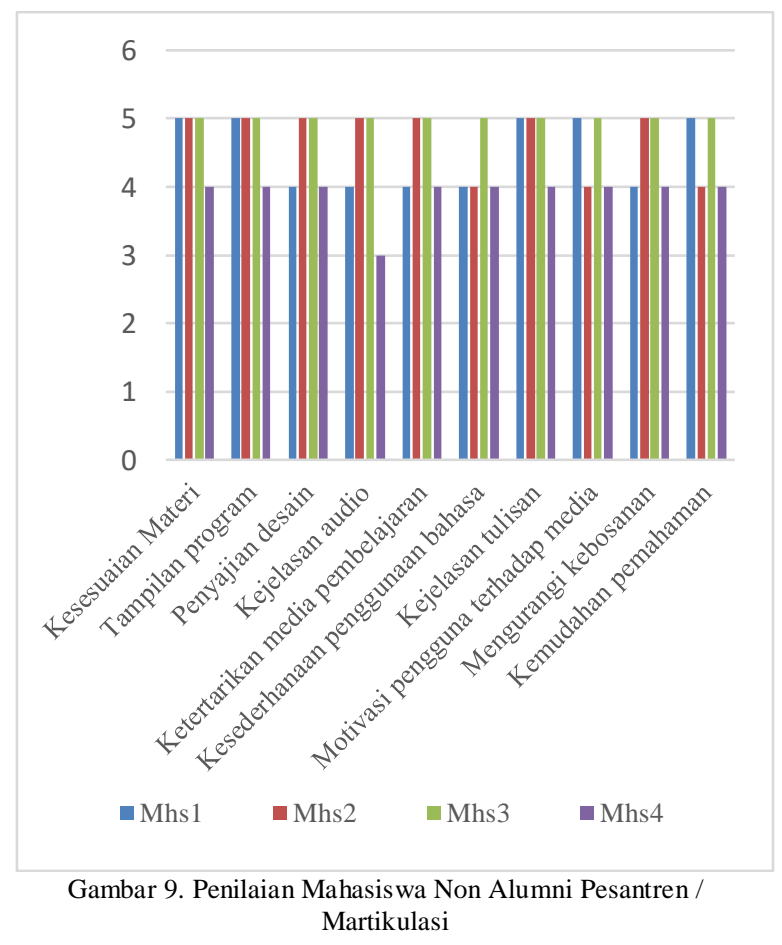

- Uji terhadap pengguna umum playstore

\begin{tabular}{|lll}
\hline Average rating & Total ratings & Ratings with reviews \\
5.000 & 18
\end{tabular}

Gambar 10. Total rating aplikasi

Berdasarkan gambar 10, jumlah rating sebanyak 27 dengan nilai tertinggi dan 18 memberikan review untuk perbaikan terhadap media pembelajaran ini.

\section{E. Maintenance}

Fase terakhir dilakukan perbaikan kesalahan dari beberapa masukan para pengguna melalui feedback email pengembang dan review yang telah tersedia di playstore. Hingga saat ini sudah mengeluarkan revisi sebanyak lebih dari 12 kali dan yang terakhir dilakukan update pada 26 Mei 2018.

\section{KESIMPULAN}

Media pembelajaran ini sesuai untuk perangkat Android berukuran minimal 4.5 inchi dan penyebaran kuisioner dengan nilai rata-rata dari ahli materi bahasa Arab memberikan nilai $100 \%$, ahli media pembelajaran 93,34\%, mahasiswa bukan alumni pesantren 90,5\%, mahasiswa prodi PBA 92\% dan pengguna umum playstore tanggal 1 sampai $20 \mathrm{Mei}$ 2018 menghasilkan rating tertinggi berjumlah 31 orang. Hasil kuisioner oleh responden menunjukkan kesesuaian media dengan pemula, akan tetapi media ini hanya bersifat membantu dan tidak bisa menggantikan peran guru dan interaksi antar guru dengan murid yang sesungguhnya. Pengembangan selanjutnya bisa menerapkan metode lain (natural, tematik, audiolingual) dan melanjutkan tahap pengguna tingkat medium dan tinggi.

\section{DAFTAR PUSTAKA}

ALI, A.Y., 2011. The Meaning of the Holy Quran. Selangor, Malaysia: Kuala Lumpur: Islamic Book Trust.

ALI BAKRI, M., 2017. Metode Langsung (Direct Method) Dalam Pengajaran Bahasa Arab. Al-Marãji, 1(1), pp.1-11.

ANDRIANI, A., 2015. Urgensi Pembelajaran Bahasa Arab Dalam Pendidikan Islam. TA'ALLUM, 3(1), pp.39-56.

BASSIL, Y., 2012. A Simulation Model for the Waterfall Software Development Life Cycle. International Journal of Engineering \& Technology, [online] 2(5), pp.2049-3444. Available at: <http://ietjournals.org/archive/2012/may_vol_2_no_5 /255895133318216.pdf>.

Developer, A., 2018. Developer Guides | Android Developers. [online] Android. Available at: <https://developer.android.com/guide/> [Accessed 14 Jul. 2018].

DIMA, A.M. AND MAASSEN, M.A., 2018. From Waterfall to Agile software: Development models in the IT sector, 2006 to 2018. Impacts on company management. Journal of International Studies, [online] 11(2), pp.315-326. Available at: <http://www.jois.eu/?438,en_fromwaterfall-to-agile-software-developmentmodels-in-the-it-sector-2006-to-2018.impacts-on-company-management>.

Indonesia, S.W.P.R., 2016. Menerima Pimpinan Pondok Modern Darussalam Gontor Wakil Presiden Republik Indonesia. [online] Wapress RI. Available at: <http://www.wapresri.go.id/menerimapimpinan-pondok-modern-darussalamgontor-2/> [Accessed 11 Jul. 2018].

MARLINA, L., 2016. Efektifitas Metode Langsung Dalam Pengajaran Keterampilan Berbicara Bahasa Arab. Al-Tsaqafa, 13(2), pp.211226. 
MURIYATMOKO, D. AND ABDULLAH, A.F., 2017. Aplikasi Tamrin Lughoh (Pembelajaran Bahasa Arab) Pondok Modern Darussalam Gontor Berbasis Mobile. Semnasteknomedia Online, [online] 5(1), pp.4-49. Available at: <http://ojs.amikom.ac.id/index.php/semnast eknomedia/article/view/1745>.

MURIYATMOKO, D., FAROUQ ABDULLAH, A. AND ADHIIM MUSYAFA', Z., 2018. Durus Al-Lughah Gontory: Interactive Arabic Mobile Learning for Beginners. IJITEE (International Journal of Information Technology and Electrical Engineering), 2(1), p.8.

NAIK, Z., 1997. The Qur'an and Modern Science. [online] Available at: $<$ http://books.google.com/books?hl=en\&lr= \&id=uld0Y-

mLoVQC\&oi $=$ fnd \&pg $=P T 4 \& d q=T H E+Q$

UR+'+AAN+AND+MODERN+SCIENCE

\&ots $=6 \mathrm{E} 9575 \mathrm{YSGO} \&$ sig $=0 \mathrm{Q}$ _FDeZ

UHsmDvsBt4dvp-3o6c>.

NUROCHIM, 2016. Sekolah Berbasis Pesantren Sebagai Salah Satu Model Pendidikan Islam Dalam Konsepsi Perubahan Sosial. AlTahrir, 16(1), pp.69-88.

PIMMER, C., MATEESCU, M. AND GR, U., 2016. Computers in Human Behavior Mobile and Ubiquitous Learning in Higher Education Settings . A Systematic Review of Empirical Studies. Computers in Human Behavior, [online] 63, pp.490-501. Available at: $<$ http://dx.doi.org/10.1016/j.chb.2016.05.05 7>.

RAHMAN, A., AINUL, T., TG, F. AND RAHMAN, A., 2012. An Evaluation Study on ASP Textbook ‘Advan Media Arabic'. In: The 8th International Language for Specific Purposes (LSP) Seminar - Aligning Theoretical Knowledge with Professional Practice. pp.223-231.

SYAFE'I, I., 2017. Pondok Pesantren: Lembaga Pendidikan Pembentukan Karakter. AlTadzkiyyah: Jurnal Pendidikan Islam, 8(1), pp.85-103.

SYARIFAH, 2016. Manajemen Kurikulum Kulliyatul Mu'allimin Al-Islamiyyah di Pondok Modern Darussalam Gontor. AtTa'dib, 11(1), pp.53-72.

THU'AIMAH, R.A., 2001. Manâhij Tadrîs alLughah al- 'Arabiyyah bi alTa'lîm al-Asâsî. Kairo: Dâr al-Fikr al-Arabi.

Web Journalist, U., 2015. UNIDA Gontor Memulai Model Pembelajaran Bahasa Arab Online. [online] UNIDA Gontor. Available at: $<$ http://unida.gontor.ac.id/unida-gontormulai-membuat-model-pembelajaranbahasa-arab-online/> [Accessed 9 Oct. 2017].
ZAID, A.H., 2012. Pendekatan Komunikatif Dalam Pembelajaran Bahasa Arab (Pengalaman Pondok Modern Darussalam Gontor). AtTa'dib, 7(2), p.311.

ZARKASYI, I. AND SYUBANI, I., n.d. Durusul Lughah Al-'Arabiyyah. Ponorogo: Trimurti Press. 
Halaman ini sengaja dikosongkan 